\title{
HISTÓRIA E O LIVRO DIDÁTICO NO ENSINO MÉDIO DE ITAPIPOCA/CEARÁ: REFLEXÕES E APONTAMENTOS ACERCA DA IDADE MÉDIA
}

\author{
Ailton Batista de Albuquerque Junior ${ }^{1}$, Jaime Teixeira de Sousa ${ }^{1}$, Marta Alves Silva ${ }^{1}$ \\ ${ }^{1}$ Instituto Federal de Educação, Ciência e Tecnologia do Ceará - IFCE \\ <ailton.junior@ifce.edu.br><jaimetsfilho@gmail.com><smart.alves@gmail.com>
}

DOI: $10.21439 /$ conexoes.v14i2.1353

\begin{abstract}
Resumo. A Idade Média é componente curricular básico do estudo de História, apresentando-se como um dos pilares para a compreensão da formação e da identidade do Ocidente. É, no que lhe concerne, vislumbrada até os dias de hoje como um período de estagnação cultural, intelectual e econômica. Tais mitos acerca desta era permeiam a historiografia desde sua concepção tradicional e vem se proliferando até os tempos contemporâneos, penetrando no senso comum e influenciando os mais diversos materiais e mídias. Tal realidade adentra nas escolas por meio dessas mídias e por meio do principal recurso utilizado no processo de ensino-aprendizagem: o livro didático. Esta pesquisa apresenta a análise realizada no espaço da Escola de Ensino Médio Coronel Murilo Serpa, tendo como referencial o livro utilizado naquela escola: História: sociedade e cidadania, 1 Ano de Alfredo Boulos Júnior (2013) e a perspectiva de quem leciona História da Idade Média na citada instituição de ensino. Por seu turno, busca obter de forma objetiva a compreensão de como a visão acerca da Idade Média é conceituada no ambiente em questão. O estudo contou com pesquisa bibliográfica, pesquisa documental e pesquisa de campo, além de utilizar um questionário com quatro questões abertas como instrumental para coleta de dados. A partir daí, constatou-se que, a despeito dos discursos que desprestigiam o período, os autores e professores presentes nesta pesquisa atuam de maneira a desconstruir os mitos e os anacronismos que se cristalizaram ao longo da História.
\end{abstract}

Palavras-chaves: História. Livro Didático. Idade Média.

\begin{abstract}
The Middle Ages is a basic curricular component of the study of history, presenting itself as one of the pillars for understanding the formation and identity of the West. It is, as far as it is concerned, envisioned to this day as a period of cultural, intellectual and economic stagnation. Such myths about this era permeate historiography from its traditional conception and has been proliferating to contemporary times, penetrating common sense and influencing the most diverse materials and media. This reality enters the schools through these media and through the main resource used in the teaching-learning process: the textbook. This research presents the analysis carried out in the space of the High School Coronel Murilo Serpa, having as reference the book used in that school: History: society and citizenship, 1st Year of Alfredo Boulos Júnior (2013) and the perspective of who teaches History of Middle Ages in the aforementioned educational institution. For its part, it seeks to obtain an objective understanding of how the view about the Middle Ages is conceptualized in the environment in question. The study counted on bibliographical research, documentary research and field research, besides using a questionnaire with four open questions as instruments for data collection. From there, it was found that, despite the discourses that discredit the period, the authors and teachers present in this research act in a way to deconstruct the myths and anachronisms that have crystallized throughout history.
\end{abstract}

Keywords: History. Textbook. Middle Ages. 


\section{INTRODUÇÃO}

A denominação do período conhecido como Idade Média denota uma interpretação tendenciosa por parte de historiadores que acabaram por influenciar toda a concepção historiográfica do Ocidente e, portanto, todo o imaginário acerca da época, forjando preconceitos e ideias mal concebidas. O conceito de Idade Média é o resultado de uma construção sistemática que visava alicerçar certo padrão de pensamento que corresponderia aos interesses de determinados historiadores e do grupo que os representava.

A História não corresponde a uma representação exata do passado, um mesmo fato ou período pode ter inúmeras representações dependendo do ponto de vista, das convicções e dos interesses de quem reproduz a informação e de quem a recebe. No caso, a Idade Média, como representação do trabalho historiográfico, pode ser considerada o produto da influência de um discurso deliberadamente construído por uma camada social em ascensão, que visava legitimar seus ideais. Durante muito tempo foi praticamente unânime a adesão à denominação pejorativa de "Idade das Trevas" para alcunhar o período medieval, transformando-o em um tempo de atraso cultural em relação à "Era das Luzes" dos filósofos iluministas.

Atualmente, conhecendo as intenções desses grupos e a relevância que o período medieval representou, busca-se desconstruir essa noção pejorativa acerca da era, apontando os avanços proporcionados na época e afirmando que a cultura não se estagnou como alguns historiadores pregaram. Nesse sentido, é válido perguntar: os livros didáticos do Ensino Médio levam à reflexão a respeito da construção subjetiva da Idade Média? Os professores buscam desconstruir esta noção apontando suas causas e identificando o contexto social, político e cultural da época dos historiadores, como elementos que pesam na produção historiográfica? Como a análise do processo historiográfico é feita em sala de aula?

Esta pesquisa é produto do interesse de investigar o modo como o período em questão é definido nos livros didáticos e seu uso pelos professores. Se há uma permanência quanto aos preconceitos que norteiam a era medieval ou se há rupturas com esta linha de pensamento, buscando desconstruir tais preconceitos.

Para a realização desta pesquisa convencionou-se escolher como espaço de investigação a Escola de Ensino Médio Coronel Murilo Serpa, com sede localizada na zona urbana de Itapipoca-CE, mais especificamente no bairro Cruzeiro, tendo como principal objeto de análise o livro didático: História: Sociedade Cidadania, $1^{\circ}$
Ano do autor Alfredo Boulos Júnior (2013), utilizado na referida escola. A opinião dos professores de História do 1 ano do Ensino Médio dessa instituição, nível em que a Idade Média é estudada, também foi considerada para os fins a que este trabalho se propõe, com o intuito de compreender como se dão as relações entre o papel do docente e a utilização do livro didático.

A principal meta desta pesquisa é discutir a necessidade de reformular as ideias acerca da temática, utilizando como recorte a ser analisado um livro didático considerado referência no município de Itapipoca-CE, adotado em uma das principais escolas de Ensino Médio da cidade. O objetivo precípuo é o de verificar como o autor do livro didático aborda a Idade Média, a partir de sua conceituação e da sua construção como período histórico, identificando, assim, o que os professores pensam a respeito do tema e como efetuam o ensino ao se apropriarem do material.

É necessário identificar como os autores de livros didáticos de História lidam com esta questão. Além da necessidade de desconstruir conceitos que, devido às novas descobertas e reinterpretações, não possuem mais razão para existir e se propagar. Torna-se importante trabalhar essa temática, visto que sua discussão leva os alunos a perceberem a fluidez que possuem o conhecimento histórico e os aspectos humanos e sociais, que regem sua produção.

\section{O livro didático em pauta}

É notório que o conhecimento histórico veiculado dentro das salas de aula faz-se efetivo por meio da utilização do livro didático, principal suporte pedagógico e fonte historiográfica para o exercício do ensino de História. Mesmo com o uso, cada vez mais crescente, de métodos e materiais alternativos como imagens, documentos, filmes, músicas, objetos do cotidiano, etc., o livro didático ainda é o recurso mais utilizado pelos professores devido principalmente ao fato deste ser, muitas vezes, o único material disponível para os próprios alunos e também pelo seu uso tradicional, enraizado e disseminado na prática pedagógica.

Tal posição, central, ocupada por este material é frequentemente discutida. Sabe-se que os livros didáticos tendem a refletir os interesses de seus produtores, reproduzindo informações passíveis de crítica por parte dos professores no momento de selecioná-los para utilização nas escolas. O conteúdo veiculado nos livros didáticos deve ser alvo de reflexão da mesma maneira que a produção historiográfica. Esta, construída na Academia, passa a integrar os livros didáticos e penetra ainda no senso comum chegando a influenciar até mesmo as 
fontes e recursos didáticos alternativos. De acordo com Pereira (2007, p. 3):

[...] é relevante discutir critérios gerais de escolha de uma publicação didática e, também, colocar em questão as representações da história que essas publicações têm produzido. Colocar em questão as representações que o livro produz não quer dizer discutir a sua qualidade, trata-se de lançar o debate sobre que visão de mundo o texto e seus acessórios estão transmitindo às novas gerações, e isso não significa determinar que o livro é bom ou que é ruim.

O uso do livro didático, portanto, não deve ser combatido. Sabendo que sua conjuntura resulta de interesses mercadológicos e seu papel é de reprodutor de informações fechadas em si. Deve-se, portanto, ressaltar sua reformulação, baseada em análise crítica ou, caso tal reforma não seja possível, por meio da atuação do professor manejando o livro como um suporte a mais, chocando ou confirmando suas informações com outras fontes e empregando o uso do livro de forma permanentemente reflexiva dentro das salas de aula. A utilização do livro didático deve, portanto, ser repensada de modo que não haja a dependência do processo de ensino-aprendizagem reduzida a um único material que carrega em si alguns problemas que se arrastam ao longo dos anos. Especificamente, dentro do ensino de História, observa-se que esta consciência tem crescido, entretanto a utilização acrítica e dependente do livro didático ainda tem se mantido, fruto deste problema já tradicional. Como afirma a autora Sonia Wanderley (2002 p. 5):

Qualquer instrumento didático utilizado no processo de ensino-aprendizagem deve ser visto como um meio e não como uma finalidade. No caso específico do ensino de História, o livro didático adquiriu a característica de ser receptáculo dos fatos importantes, coleção de imagens e acontecimentos que foram considerados significativos pelos responsáveis pela vulgarização de uma perspectiva simplista de História, cuja leitura a conceitua como ciência do passado. Embora essa caracterização já encontre detratores importantes no meio acadêmico e editorial, ainda é forte no senso comum e produz um amálgama difícil de ser desfeito entre alunos e muitos docentes da Escola Básica.

Tendo em vista esta realidade, cabe ressaltar a visão de Idade Média que tal suplemento didático reproduz. O período medieval tem sido definido como uma época marcada pela estagnação científica, econômica, social e cultural que atrasou o desenvolvimento da civilização ocidental. Estes rótulos foram fortemente enraizados no seio do senso comum, produzindo na mentalidade das pessoas a noção de que a Idade Média foi um tempo de completo "obscurantismo".

\subsection{A (re)construção da Idade Média}

Atualmente, se reconhece o profundo legado da Idade Média, para além do "atraso" relacionado ao modo de economia feudal e a força do poder religioso. Sabe-se que o tão difamado período teve o papel de progenitor da sociedade ocidental contemporânea, fazendo com que seu estudo não seja essencial apenas para a compreensão da história da Europa, mas para entender a construção da identidade dos povos ocidentais, os herdeiros da cultura europeia, fruto de séculos de colonização. Como atesta o historiador Hilário Franco Junior (2001, p. 215):

\begin{abstract}
Após os exageros denegridores dos séculos XVI-XVII e os exaltadores do século XIX, hoje temos uma visão mais equilibrada sobre a Idade Média. É verdade que a divulgação que ela conheceu em fins do século XX fora dos meios acadêmicos - inúmeras publicações científicas e ficcionais, filmes, discos, exposições, turismo etc. - nem sempre implicou uma melhor compreensão daquele período. Mas reflete um dado essencial: a percepção que se tem da Idade Média como matriz da civilização ocidental cristã. Diante da crise atual dessa civilização, cresce a necessidade de se voltar às origens, de refazer o caminho, de identificar os problemas. Enfim, de conhecer a Idade Média para conhecer melhor os séculos XX - XXI.
\end{abstract}

Até mesmo a cunhagem do termo "Idade Média" tem relação com os preconceitos que iriam influenciar a historiografia durante séculos, logo, penetrando nas escolas e na sociedade. O "médio", colocado na tradicional divisão da história em idades, está inserido entre o "antigo" e o "moderno". Esta organização cronológica, criada por um único autor, terminou por ser levemente alterada ou adaptada e penetrou na produção historiográfica sendo influente até os dias atuais, sobretudo, no ensino. Segundo Nascimento (1992, p. 8-9):

\footnotetext{
A Idade Média também foi inventada. Um pedagogo alemão chamado Cristoph Keller, em latim Cellarius (1638 - 1707), consagrou a história ocidental em antiga, medieval e moderna. Consagrou também a ideia que se generalizou sobre o período medieval. Keller ou Cellarius escreveu três manuais: um de história antiga (1685), um de história da idade média (1688) e um de história nova (1696). A idade média, segundo Keller, estende-se da época do imperador Constantino (324) até a tomada de Constantinopla pelos turcos (1453). Se, em vez da primeira data, adotarmos a da tomada de Roma pelo chefe germânico Odoacro em 476, teremos a periodização corrente nas escolas.
}

Já Franco Junior (2001, p. 9) aponta em sua pesquisa raízes mais distantes no tempo para as conceituações negativas que rotulam o período em destaque.

Admirador dos clássicos, o italiano Francesco Petrarca (1304-1374) já se referira ao período anterior como de 
tenebrae: nascia o mito historiográfico da Idade das Trevas. Em 1469, o bispo Giovanni Andrea, bibliotecário papal, falava em media tempestas, literalmente "tempo médio", mas também com o sentido figurado de "flagelo", "ruína". A idéia enraizou-se quando em meados do século XVI Giorgio Vasari, numa obra biográfica de grandes artistas do seu tempo, popularizou o termo "Renascimento". Assim, por contraste, difundiram-se em relação ao período anterior as expressões media aetas, media antiquitas e media tempora.

Tais perspectivas fundamentaram-se em certos vultos e se enraizaram na historiografia fazendo surgir ideias equivocadas e antiquadas partindo de personagens com determinados pontos de vista e determinados anseios, cuja concretização demandava a construção de certa versão da História que justificasse seus objetivos e ideais. Entre estes personagens estão os protestantes, que criticavam a hegemonia católica, os reis absolutistas e a burguesia ascendente, que apontavam as falhas do sistema político e econômico embasado no feudalismo (Franco Junior, 2001).

Há a necessidade de "recriar" a Idade Média, reconhecer sua real importância para a formação do Ocidente. Pesquisas e novas perspectivas tem permitido esta mudança de atitude em relação ao tão difamado período e estas novas ações devem adentrar nos manuais escolares e suscitar a crítica, evitando as deficiências analíticas inerentes ao anacronismo.

\begin{abstract}
Mais do que novos objetos de ensino, complexificando o papel dos professores e a escritura dos livros didáticos, os estudos medievais exigem de professores e autores uma mudança de olhar para a história e, particularmente, para a Idade Média. Ao invés de continuar a olhar para o medievo tendo como referência os conceitos do presente, exige-se que a leitura do passado medieval aconteça a partir do modo como os medievais olhavam para si próprios. (PEREIRA 2007. p. 8)
\end{abstract}

Portanto, reconhecendo a subjetividade na construção do conceito histórico de Idade Média e sabendo da necessidade de reconstruir este conceito ou de pelo menos salientar o fato de que esta proposição foi "humanamente" construída, percebe-se a importância (ou dependência) do livro didático para o processo de ensinoaprendizagem de História. Destarte, cabe ressaltar a análise do ponto de vista crítico que visa obter uma avaliação acerca de sua qualidade, contribuindo para um ensino de História pautado na reflexão, na investigação e no questionamento frequente, em detrimento de um ensino embasado na simples reprodução mecânica.

\section{Metodologia}

No entendimento de Fonseca (2002), a metodologia é o mesmo que organização ou investigação, isto é, o caminho a ser percorrido para se realizar uma pesquisa ou um estudo.

Nessa busca, utilizou-se de pesquisa bibliográfica, isto é, uma revisão da literatura já publicada que diz respeito à temática em estudo. Conforme esclarece Boccato (2006, p. 266):

\begin{abstract}
a pesquisa bibliográfica busca a resolução de um problema (hipótese) por meio de referenciais teóricos publicados, analisando e discutindo as várias contribuições científicas. Esse tipo de pesquisa trará subsídios para o conhecimento sobre o que foi pesquisado, como e sob que enfoque e/ou perspectivas foi tratado o assunto apresentado na literatura científica. Para tanto, é de suma importância que o pesquisador realize um planejamento sistemático do processo de pesquisa, compreendendo desde a definição temática, passando pela construção lógica do trabalho até a decisão da sua forma de comunicação e divulgação.
\end{abstract}

Nessa acepção, outro autor corrobora a premissa supracitada ao afirmar que a pesquisa bibliográfica é realizada:

A partir do levantamento de referências teóricas já analisadas, e publicadas por meios escritos e eletrônicos, como livros, artigos científicos, páginas de web sites. Qualquer trabalho científico inicia-se com uma pesquisa bibliográfica, que permite ao pesquisador conhecer o que já se estudou sobre o assunto. Existem, porém pesquisas científicas que se baseiam unicamente na pesquisa bibliográfica, procurando referências teóricas publicadas com o objetivo de recolher informações ou conhecimentos prévios sobre o problema a respeito do qual se procura a resposta (FONSECA 2002 p. 32)

No que tange à pesquisa retrocitada, o autor em comento valeu-se de escritores renomados que lidam com temas relacionados ao ensino de História, ao uso do livro didático e ao estudo da Idade Média, inclusive, utilizando-se de levantamentos a partir dos personagens que atuam diretamente no processo aqui analisado, no caso, os docentes de História, considerando suas perspectivas como elemento essencial para a compreensão do que se objetiva analisar.

Foi indispensável a pesquisa de cunho documental que, conforme Gil (2008), é semelhante à pesquisa bibliográfica, tendo como diferença principal o trabalho com materiais (documentos) que ainda não receberam tratamento analítico: o livro didático, no caso em questão.

Ademais contou com uma pesquisa de campo, uma vez que essa se realiza por meio da coleta de dados junto a pessoas, com o recurso de diferentes tipos de pesquisa (FONSECA, 2002), sendo utilizada a técnica de investigação com o questionário de perguntas subjetivas (em apêndice) que segundo Gil (2008) é composto por um 
número mais ou menos elevado de questões apresentadas por escrito às pessoas, tendo por objetivo o conhecimento de interesses, crenças e/ou sugestões. Esse instrumental foi aplicado nos dias 14, 21 e 22 de junho de 2016.

Os sujeitos da pesquisa foram os 03 professores de História que lecionam no $1^{\circ}$ ano da E.E.M. Cel. Murilo Serpa, a saber: Elisangela Teixeira Fonseca, Rodrigues Sampaio e José Messias de Oliveira. A presente pesquisa, buscou compreender suas opiniões acerca da temática discutida neste trabalho e entender a relação entre sua prática histórico-pedagógica e a utilização do suporte teórico utilizado na escola.

Outrossim, essa pesquisa está configurada de acordo com a resolução $n^{\circ} 510$, de 07 de abril de 2016 em que a mesma dispõe sobre as normas aplicáveis a pesquisas em Ciências Humanas e Sociais cujos procedimentos metodológicos envolvam a utilização de dados diretamente obtidos com os participantes ou de informações identificáveis ou que possam acarretar riscos maiores do que os existentes na vida cotidiana.

\section{Análises e Discussão dos Resultados}

"Feudalismo europeu: gestação e crise." É com esta frase que o historiador Alfredo Boulos Júnior (2013) delimita em seu livro didático História: sociedade \& cidadania, o início da temática Idade Média. Este livro é o principal material didático utilizado pelos alunos e professores de História da E.E.M. Cel. Murilo Serpa. Percebe-se que o autor quebra paradigmas ao não utilizar o tradicional método de divisão da História em Idades e também por não iniciar o tema por um título cujo nome dê alguma ideia de Idade Média. O leitor percebe a inserção ao tema ao se deparar com uma das principais características do período, no caso, o sistema feudal, o que paralelamente pode ser considerado como manutenção do estudo de temas tradicionais.

Outra diferenciação notável é o modo como ele busca situar os alunos no tema. A primeira página do referido capítulo (p. 205) apresenta uma fotografia do interior da Universidade de Bolonha na Itália seguida de um questionário reflexivo a respeito das universidades. As três primeiras perguntas são: (I) "Você já visitou uma universidade?”; (II) "Sabia que o número de brasileiros que conseguem concluir um curso universitário ainda é muito pequeno?"; (III) "Sabia, também, que a universidade possui autonomia para organizar o ensino, a duração dos estudos, as modalidades de exames, entre outras questões?". Tais perguntas, como explanado nas próprias orientações aos professores usuários do livro, visam dar ao aluno a noção da relevância que as universidades possuem. E, na quarta e última pergunta, percebe-se que o autor busca uma nova relação com o período estudado: "E que essa instituição [Universidade], tão sonhada por jovens do mundo todo, é uma invenção medieval?"

Observa-se que Boulos inicia sua explanação acerca da Idade Média, suscitando, através de indagações, a referência que esse período, supostamente marcado pela ignorância e pela superstição, teve para o cultivo das ciências. A partir deste ponto inicial, vale ressaltar a atuação do professor como mediador entre os discentes e o documento utilizado, visto que a página inicial do capítulo oferece subsídios que podem ser usados nas discussões iniciais. Para além da Universidade, apontada no livro, a professora Elisangela Teixeira Fonseca (2002) também enfatizou os aspectos positivos cujas origens são atribuídas ao período medieval:

\begin{abstract}
A atribuição do termo "Idade das Trevas" para definir os 1000 anos da Idade Média é conceito errôneo, uma vez que tal definição remete a este período da história da humanidade como um tempo marcado determinante pela fé e sem a utilização da razão pelos seres humanos. Neste sentido tal concepção deve ser analisada a fim de perceber que o mundo não mergulhou em uma era de escuridão, sem qualquer forma de avanço no campo intelectual e científico, uma vez que sabemos que neste período houve muitas invenções, que fazem parte da nossa realidade como o botão, a pólvora e a criação das universidades, além de estudos no campo da matemática, astronomia, química, física.
\end{abstract}

Na página seguinte, Boulos Júnior (2013, p. 206) explicita o significado do conceito de Idade Média definindo-o pela sua delimitação tradicional, envolvendo as quedas do Império Romano do Ocidente e do Oriente, no entanto, o autor ressalta que: "Essa periodização, que tem como marco inicial o século $\mathrm{V}$ e o final do século $\mathrm{XV}$, tem recebido várias críticas. Nós a apresentamos por ser muito usada em livros, revistas e jornais." O autor, portanto, afirma que a cronologia empregada no estudo da Idade Média em seu livro será regida pelas concepções tradicionais. Contudo, Boulos justifica essa adesão evitando que tal periodização seja concebida como uma verdade absoluta. Tal atitude, por mais simples que pareça, representa um importante passo para a desmistificação da Idade Média e identificação das possibilidades da historiografia, coerente com a opinião dos professores de História, ajudando-os em seus intuitos. Como afirma o professor Flávio Rodrigues Sampaio (2016):

\footnotetext{
A história às vezes é interpretação dos fatos. Tanto de quem produz e de quem tem acesso às produções. A disciplina de História deve ter uma das propostas, possibilitar a criticidade dos educandos. Fato esse que passa pelo
} 
professor. Então o professor deve apresentar as possíveis interpretações variadas de um fato ou acontecimento despertando nesses educandos uma análise particular.

Ainda dentro desta lógica, a professora Elisangela (2016) responde que:
[..] é indiscutível que os professores de História devem explicar para os alunos que não existem as ditas "ver- dades absolutas", uma vez que, não trabalhamos com uma disciplina exata. Assim a historiografia muda de acordo com as necessidades e com novos fatos, cren- ças, valores entre outros. Conceitos indiscutíveis dentro de uma determinada sociedade e períodos como o termo Pré-história, "Idade das Trevas", podem sim ser reavali- ados, o que foi dito em uma determinada época pode ser questionado e aprimorado.

Na mesma página, Boulos Jr, dando continuidade a este processo de reflexão, em um texto situado no tópico para refletir expõe a origem do termo Idade Média. Nesse texto ele aborda as intenções dos pensadores que se identificavam como modernos, suas ideias em relação ao período anterior que classificavam como um período de trevas entre o Antigo e o Novo. Boulos encerra o texto apresentando uma periodização alternativa construída pelo historiador francês Jacques Le Goff, no qual este descreve sua forma original de delimitar e classificar a Idade Média. No fim do tópico, Boulos Júnior coloca algumas questões reflexivas, a respeito do texto, para serem respondidas pelos alunos. Desse modo, o autor reavalia o conhecimento acerca do assunto, expondo que há outras vertentes metodológicas para estudar o medievo mesmo que ele tenha optado, por ser reconhecidamente mais conveniente, manter a forma tradicional. Nesse sentido, pode-se salientar a afirmação do professor Flávio (2016) que diz que: “[...] avaliar ou reavaliar é de suma importância não só para se 'saber' do assunto, mas, de possibilitar a apropriação desse assunto e o desenvolvimento de análise, reflexão e criticidade dos mesmos".

Ao longo do capítulo, percebe-se uma veiculação tradicional das informações, fato evidente na organização da exposição dos conteúdos. O autor escreve a respeito das origens e das características do modelo feudal, estabelece como a divisão social era mantida entre servos, nobres e clérigos analisando o papel social destes atores, analisa o processo de ressurgimento do comércio e da urbanização e ressalta o poder da Igreja Católica enfatizando nesse aspecto a temática referente às Cruzadas. Avaliando o livro, Elissangela (2016) afirma que:

O livro didático ainda permanece com algumas defasagens, entretanto é válido salientar que ao longo do capítulo dedicado ao estudo deste período podemos perceber a utilização de uma visão mais contemporânea sobre tal assunto, sendo destacado alguns aspectos que referenciam a Idade Média como um tempo onde ocorreu vários avanços para a humanidade, mesmo que durante alguns anos tenham sido "escondidos". No entanto, não posso negar que o livro analisado permanece com a maioria dos textos focados em falar sobre feudalismo, poder da Igreja católica e Inquisição.

Ou seja, a professora avalia o livro como positivo, mas não nega que o autor acabou por utilizar um método tradicional de exposição e estudo dos temas, não apresentando tantas inovações. Já o professor José Messias de Oliveira (2016), salientando a condensação dos conteúdos no livro de Boulos Jr, afirma que:

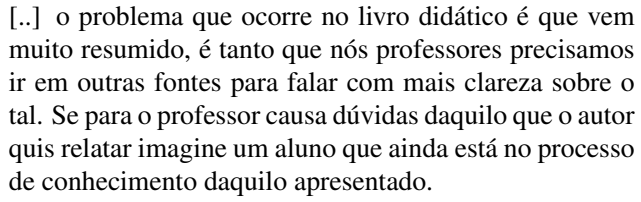

[..] o problema que ocorre no livro didático é que vem muito resumido, é tanto que nós professores precisamos ir em outras fontes para falar com mais clareza sobre o tal. Se para o professor causa dúvidas daquilo que o autor quis relatar imagine um aluno que ainda está no processo de conhecimento daquilo apresentado.

Em síntese, o livro didático História: sociedade \& cidadania, $1^{\circ}$ ano de Alfredo Boulos Júnior, representa uma tentativa de oferecer uma noção crítica acerca da formação do conceito de Idade Média, explorado de forma dinâmica pelo professor, com a intenção de rever os arcaicos conceitos a respeito da época medieval pode ser alcançado. Por outro lado, o autor utiliza métodos e conceitos tradicionais na exposição do assunto, cabendo ressaltar que essa "escolha" foi justificada pelo autor em função do uso já enraizado de tais métodos de periodização, refletidos nas formas de estudar a Idade Média. É válido salientar também que, Boulos Júnior não aderiu às rotulações denegridoras que impuseram à Era medieval.

Quanto às opiniões expostas pelos professores, é possível perceber com certo otimismo que no ambiente em que atuam, na escola Cel. Murilo Serpa, é desenvolvido um trabalho que visa ao questionamento crítico, inclusive quanto ao tema Idade Média, tanto quanto na opinião que estes têm do livro; longe de ser uma total concordância sem ressalvas, mas uma interpretação que busca ser independente na medida do possível. Percebe-se que a relação entre o método e o material obedece a critérios definidos pelos próprios professores de História, cientes da importância desta mediação para o processo de ensino-aprendizagem.

\section{Considerações Finais}

A Idade Média é mais um período da História cujo real entendimento possibilita uma compreensão mais clara da civilização ocidental. Esta época foi percebida de maneira praticamente unânime como um tempo de 
"trevas" e ignorância. Atualmente, após a reinterpretação do período e a identificação dos interesses dos responsáveis pelo forjamento de tais rótulos, busca-se a difusão de uma nova visão a respeito dos tempos medievais.

Esta pesquisa teve como pressuposto demonstrar que é necessário que o método histórico seja avaliado e entendido pelo seu principal público-alvo. Ou seja, expor que o conceito de Idade Média foi o resultado de uma construção subjetiva, possibilitando que os alunos possam perceber de forma crítica como a historiografia é feita, atendendo assim às demandas que não se limitam apenas ao período em questão, mas a todo o ensino de uma disciplina que se propõe como fundamental à construção do senso crítico. A escolha do tema "Idade Média", portanto, serviu não como um fim em si, mas como um meio para ressaltar a necessidade de se trabalhar esse processo de reconhecimento na construção da História enquanto produto inexato.

Por meio deste trabalho foi possível avaliar que o autor Alfredo Boulos Júnior, em seu livro didático História, Sociedade \& Cidadania, optou por apresentar a maneira com a qual a história da Idade Média foi escrita. Ele não apresenta em sua obra um período estático a ser estudado de forma mecânica visando uma aquisição de informações, também, meramente mecânica. Boulos Jr. opta por identificar como o conceito de Idade Média foi construído partindo da perspectiva de seus produtores.

Quanto aos demais textos e métodos como o cronológico, há uma permanência na tradicional forma de se estudar o período medieval, motivada pela presença forte destes conceitos no qual qualquer mudança poderia até mesmo prejudicar a compreensão do aluno e o trabalho do professor, tendo em vista o conceito já tão enraizado a respeito da Idade Média. No mais, o que se pode fazer, pelo visto, é buscar chocar todo o leque disponível de informações e versões de uma mesma época, mas não de uma mesma história.

Quanto aos professores da Escola Cel. Murilo Serpa, percebeu-se o quanto estão distantes das perspectivas tradicionais que este trabalho buscou criticar, e das tendências em depender excessivamente do livro didático. Os docentes desta escola sustentam um discurso no qual se percebe uma visão atualizada acerca do período medieval, entendido a partir da necessidade de demonstrar o caráter controverso e múltiplo do discurso histórico e a capacidade de compreender e utilizar o livro didático, considerando seus pontos positivos e reconhecendo suas deficiências.

\section{REFERÊNCIAS}

BOCCATO, V. R. C. Metodologia da pesquisa bibliográfica na área odontológica e o artigo científico como forma de comunicação. Rev. Odontol. Univ. Cidade São Paulo, São Paulo, v. 18, n. 3, p. 265-274, 2006.

Boulos Júnior, A. História: sociedade \& cidadania. 1. ed. São Paulo: FTD, 2013.

BRASIL. Resolução No 510, de 07 de abril de 2016. Dispõe sobre as normas aplicáveis a pesquisas em Ciências Humanas e Sociais cujos procedimentos metodológicos envolvam a utilização de dados diretamente obtidos com os participantes ou de informações identificáveis ou que possam acarretar riscos maiores do que os existentes na vida cotidiana. 2016. Disponível em: <http://conselho. saude.gov.br/resolucoes/2016/Reso510.pdf>. Acesso em: 02 jan. 2017.

FONSECA, J. J. S. Metodologia da pesquisa científica. Fortaleza, 2002. Apostila.

Franco Junior, H. A Idade Média: Nascimento do

Ocidente. 2. ed. São Paulo: Brasiliense, 2001.

GIL, A. C. Como elaborar projetos de pesquisa. 4. ed. São Paulo: Atlas, 2008.

NASCIMENTO, C. A. R. D. O que é Filosofia

Medieval. 1. ed. São Paulo: Brasiliense, 1992.

PEREIRA, N. M. Representações da idade média no livro didático. In: Simpósio Nacional de História. 24. ed. São Leopoldo-RS: Associação Nacional de História - ANPUH, 2007. p. 1-9.

WANDERLEY, S. Repensando o ensino da história, produzindo conhecimento. Caderno de Graduação Ensino e formação de professores na perspectiva das licenciaturas em Ciências Humanas. Rio de Janeiro: UERJ, Departamento de Ensino de Graduação, v. 4, n. 1, p. 36-43, 2002. 